\title{
Electromechanical Drivetrain in Agricultural Tractors
}

\author{
Stanislav Florentsev* \\ "Ruselprom - ElectricDrive" Ltd., RUSSIA
}

\begin{abstract}
In the report there are shown results of design and field tests of the wheeled agricultural tractors with electromechanical drivetrains (EMD): 300 h.p. tractor Belarus-3023 (with gear-drive), 160 h.p. tracked tractor (with individual board-drives) and 455 h.p. wheeled tractor (with individual drive of four wheels). There are presented schemes of complete traction electric equipment sets (TEES) for these tractors, parameters and characteristics of all their components: generators, traction motors, power and control electronics, auxiliary power systems and cooling; control algorithms for the bottom and top levels.
\end{abstract}

KEYWORD: electromechanical drivetrains; wheeled agricultural tractors; tracked tractor; traction electric equipment sets

\section{H.P. EMD-EQUIPPED TRACTOR WITH GEAR-DRIVE}

Main results of the development and trials of the concept-tractor and pre-series lot of tractors Belarus3023 have been presented in [1-2]. One of the preseries tractors was demonstrated at the exhibition AGRITECHNICA-2009 and was awarded a silver medal for innovations of the DLG society (Figure 1).

Chief Editor of the PROFI magazine has fulfilled its independent field tests of the tractor Belarus-3023 which results were published in the [3].

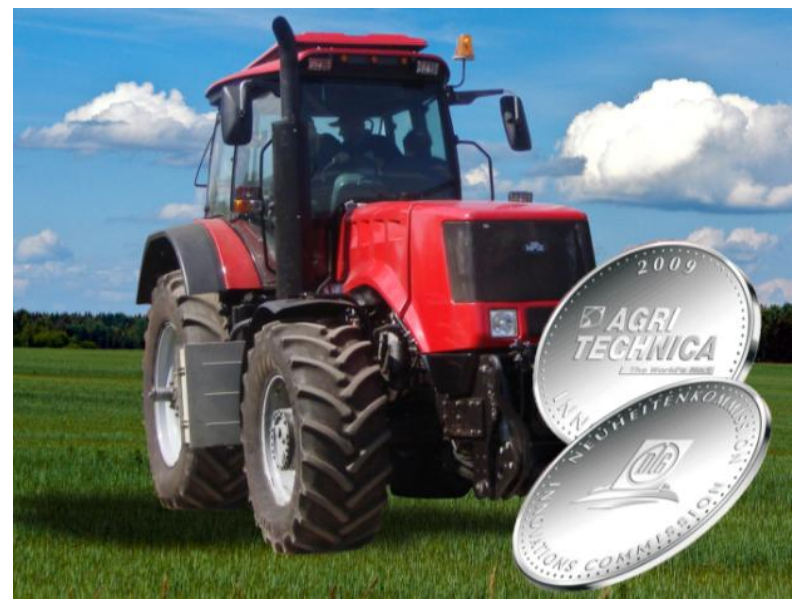

Figure 1EMD-equipped wheeled tractor Belarus-3023 with gear-drive
TEES of the tractor Belarus-3023 includes (Figure 2):

- traction asynchronous AC motor - generator (AMG);

- traction asynchronous motor (TAM) for gear-drive;

- power electronics block (PEB) containing converters with microprocessor control system (mContr) for AMG and TAM, bi-directional galvanically decoupled DC/DC converter (for battery charge, on-board auxiliary power supply and DC bus charge) and systems of monitoring, diagnostics and protection of high-voltage circuits;

- high level controller (HLC) for control of power flows and traction with control and indication means (information display) in the driver's cabin.

\subsection{Application of the EMD allows to:}

- improve technical and economical parameters of the tractor;

- reduce dynamical loads on tractor and diesel units;

- reduce slipping of wheels, cut fuel consumption per performed work (by up to $30 \%$ );

- provide continuous variation of speed of the tractor and aggregated tools;

- reduce cost of maintenance, repair, spare parts;

- increase total reliability, controllability and comfort.

\footnotetext{
* Dr. Stanislav N. Florentsev
} 


\subsection{Advantages of the EMD-based design:}

- Effective, simple and reliable CVT.

- Only two modes chosen manually ("field" or "road").

- Automatic switching by a friction coupling providing effective acceleration in traffic mode.

- Possibility of operation with high efficiency in the overall tractor speed range.

- Efficient control of diesel operating mode depending on power demand.
- Availability of modes of electric braking with motion energy transfer to diesel, tractor holding on ground ascents and descents, crawling for the pre-set small distance.

- Effective liquid cooling of the electric drive.

\subsection{Advantages in the comfort and controllability:}

- Simplicity and convenience of gearbox controls,

- Availability of several drivetrain control modes:

- setup of the tractor's traction force from pedal,

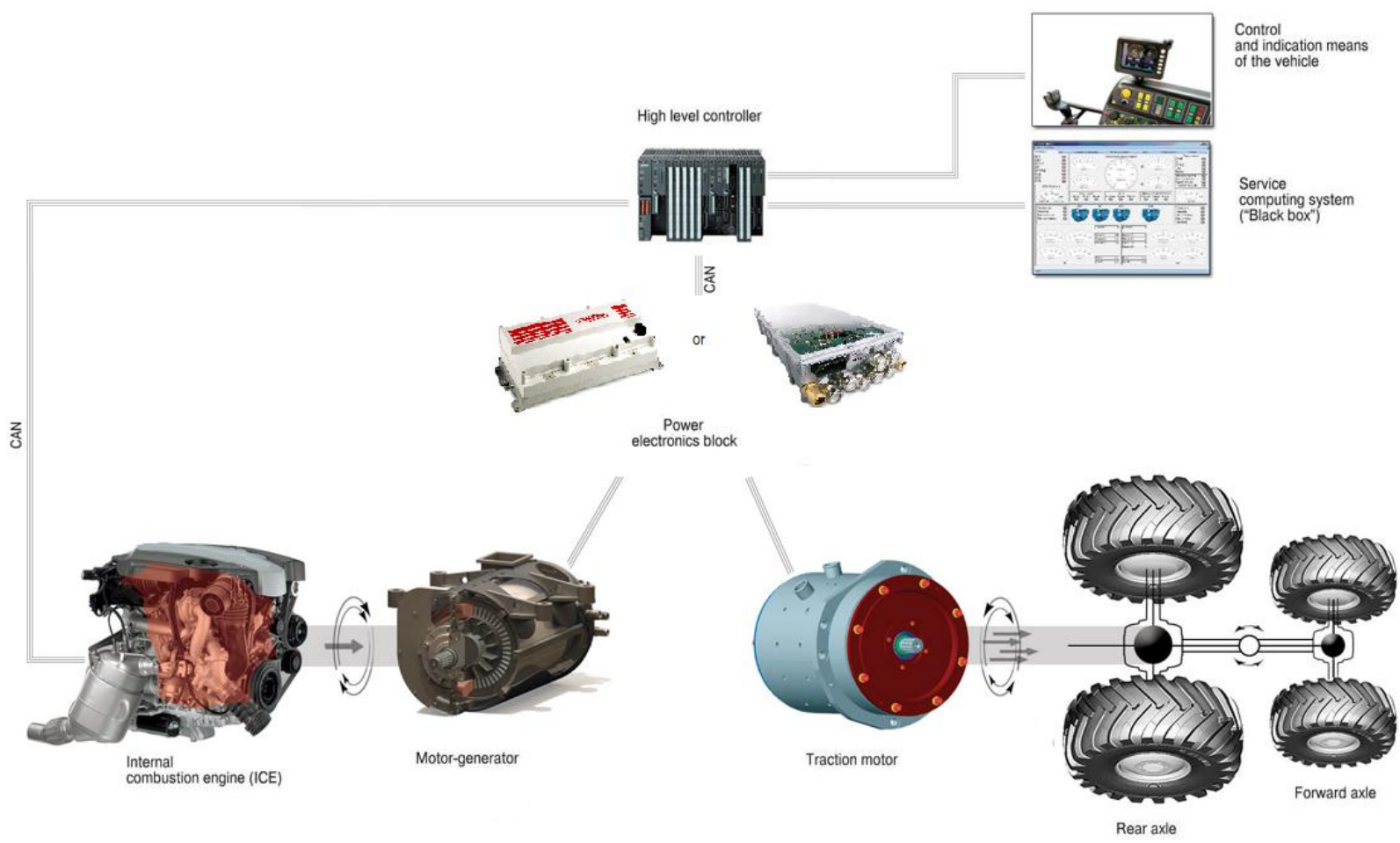

Figure 2 Block-diagram of the TEES of the tractor Belarus-3023

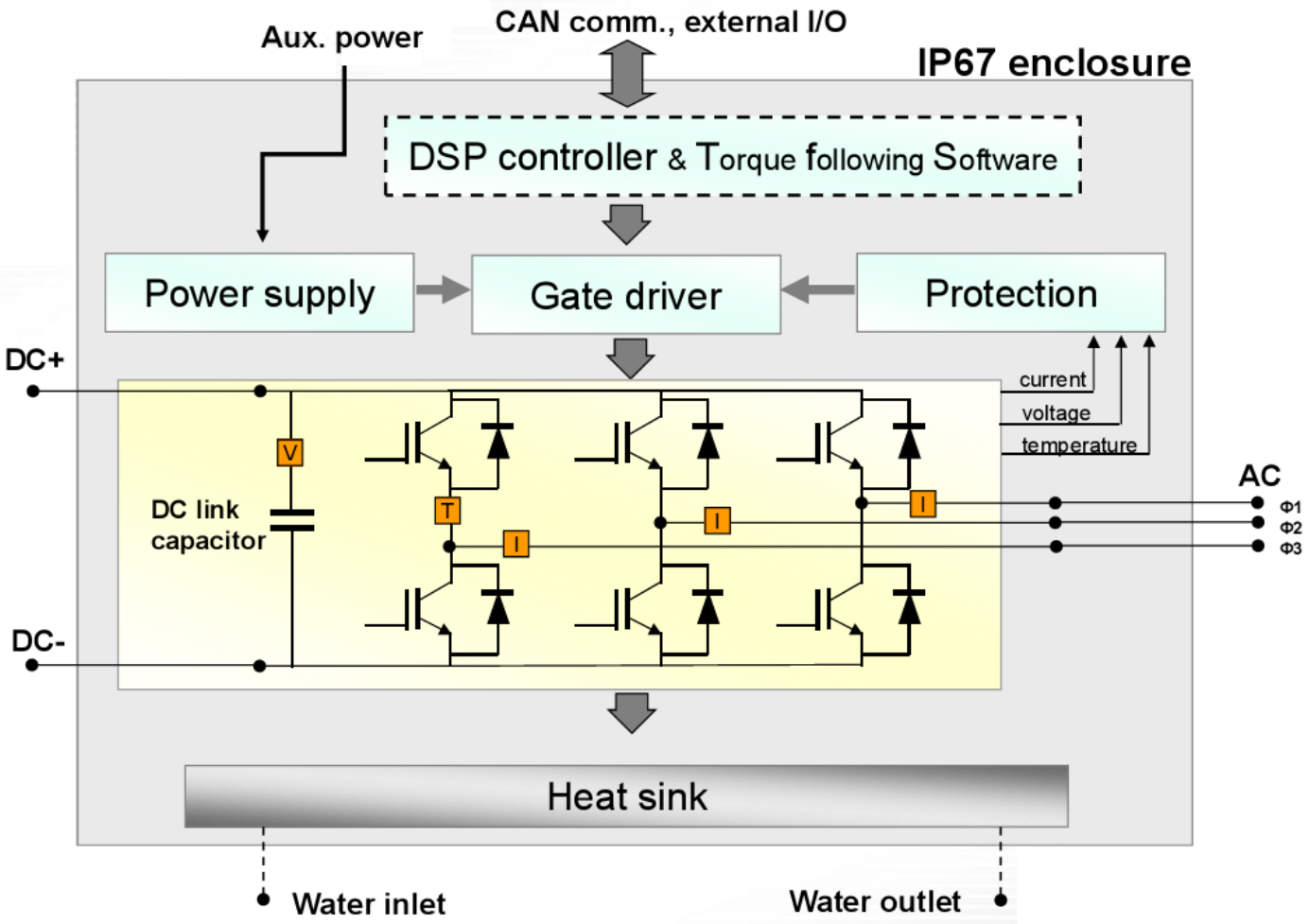



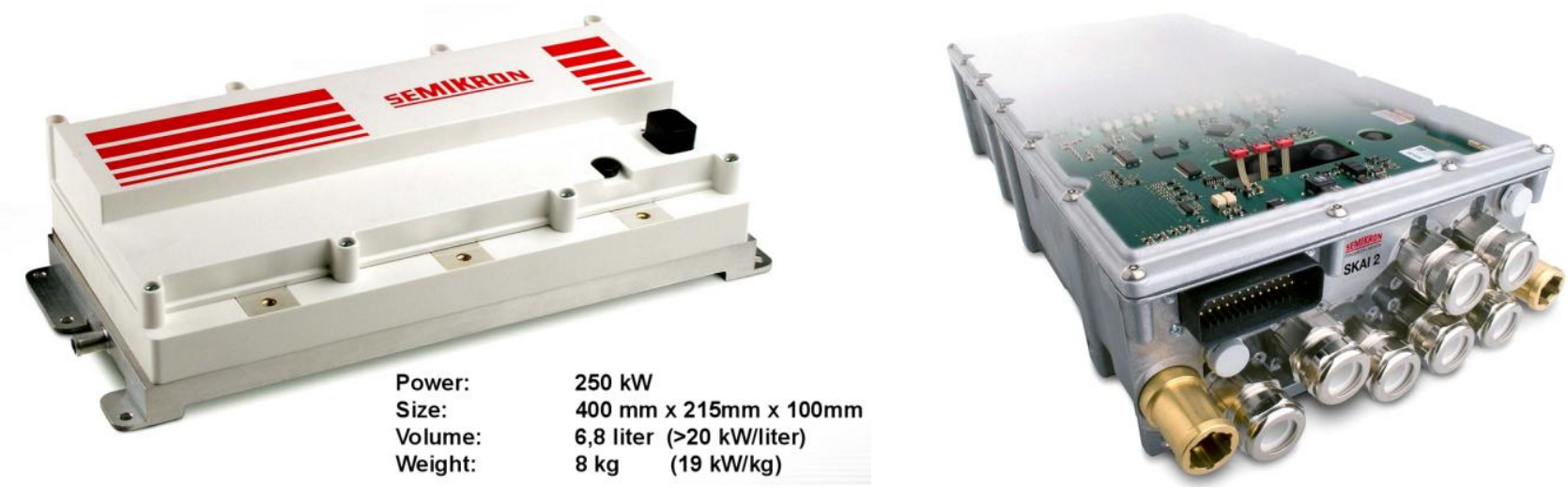

Figure 3 Power converter modules SKAI applied in the PEB (left - SKAI 1, right - SKAI 2)

- speed setup from joystick with possibility of rough and exact adjustment,

- tractor positioning with possibility of diesel rotation speed control from a pedal in this mode.

- Possibility of independent control of the diesel rotation speed and tractor's speed with the PTO 'on',

- Ease of variation of the movement direction including at riding.

Software of controllers was revised twice which have improved its reliability and quality, accuracy and response time for the driver's setup, providing more comfortable control of the tractor. Controllers of AMG and TAM apply vector control system.

For power converters there are used modules SKAI-1 or SKAI-2 from Semikron (Figure 3).

For diesel control applying multi-parameter characteristic with the fuel consumption map there was provided minimal fuel consumption in all tractor's operation modes.

Experimentally measured total TEES efficiency from the AMG shaft to the TAM shaft in the tractor travel speed range $9-12 \mathrm{~km} / \mathrm{h}$ is $87 \%$.

\section{H.P. EMD-EQUIPPED TRACKED TRACTOR WITH INDIVIDUAL BOARD- DRIVE}

RUSELPROM Corp. has developed TEES for a sample tracked tractor based upon a serial industrial tracked tractor Belarus-1502 equipped by the mechanical drivetrain.

The task of the development was to create a stepless drivetrain providing:

- similar characteristics of forward and rearward movement of the tractor;

- braking by the ICE (transfer of the power from tracks to the diesel shaft) within the allowed power of the diesel;

- sharing traction/braking torque among tractor's boards e.g. steering including turn around;

Main TEES components are:

- traction asynchronous AC generator (motor generator) (AMG);
- two traction asynchronous motors connected by reductors to board-drives (TAM);

- power electronics block (PEB) containing converters with microprocessor control system (mContr) for AMG and TAM;

- cooling system for PEB, AMG and TAMs;

- on-board auxiliary power supply;

- high level controller (HLC) for control of power flows and traction with control and indication means in the driver's cabin.

Besides control algorithms, each of electric drives has a standard set of failure protections of the traction electric drive which includes protections from:

- overheating of traction generator, asynchronous motors, power converters;

- degradation (destruction) of the insulation of highvoltage circuits and stator windings;

- overvoltage at the DC bus;

- overcurrents, overvoltages, overtemperatures of power converters and stator windings of motorgenerator and asynchronous motors;

- loss of control of any of electric drives by the HLC.

\section{TRACTOR 455 H.P. WITH INDIVIDUAL DRIVE FOR FOUR WHEELS}

High-power agricultural wheeled articulated-frame tractor Kirovetz-9450 with 455 h.p. diesel (Figure 4) equipped with the TEES with four motorParameters of the tractor with EMD and four motorwheels.

The developed TEES for the high-power agricultural wheeled tractor Kirovetz-9450 with the AC/AC electric drive includes:

- traction asynchronous AC motor - generator (AMG);

- four traction asynchronous motors (TAM) for wheel-drives;

- power electronics block (PEB) containing converters with microprocessor control system (mContr) for AMG and TAMs, and bi-directional galvanically decoupled DC/DC converter (for battery 
charge, on-board auxiliary power supply and DC bus charge);

- high level controller (HLC) for control of power

flows and traction;

- control and indication means (information display)

in the driver's cabin;

- cooling system for AMG, TAMs and PEB;

- SCS for adjustment, monitoring, and diagnostics of the TEES.
Block-diagram of the developed electric drivetrain is shown in the Figure 4.

The conducted tests proved the accepted technical decisions concerning electric machines and electronic components of the TEES and its operability as a whole. Total efficiency of the EMD (from the ICE shaft to wheels) is indicated at a level of $82 \%$ practically through the whole range of tractor's speeds and operation modes.

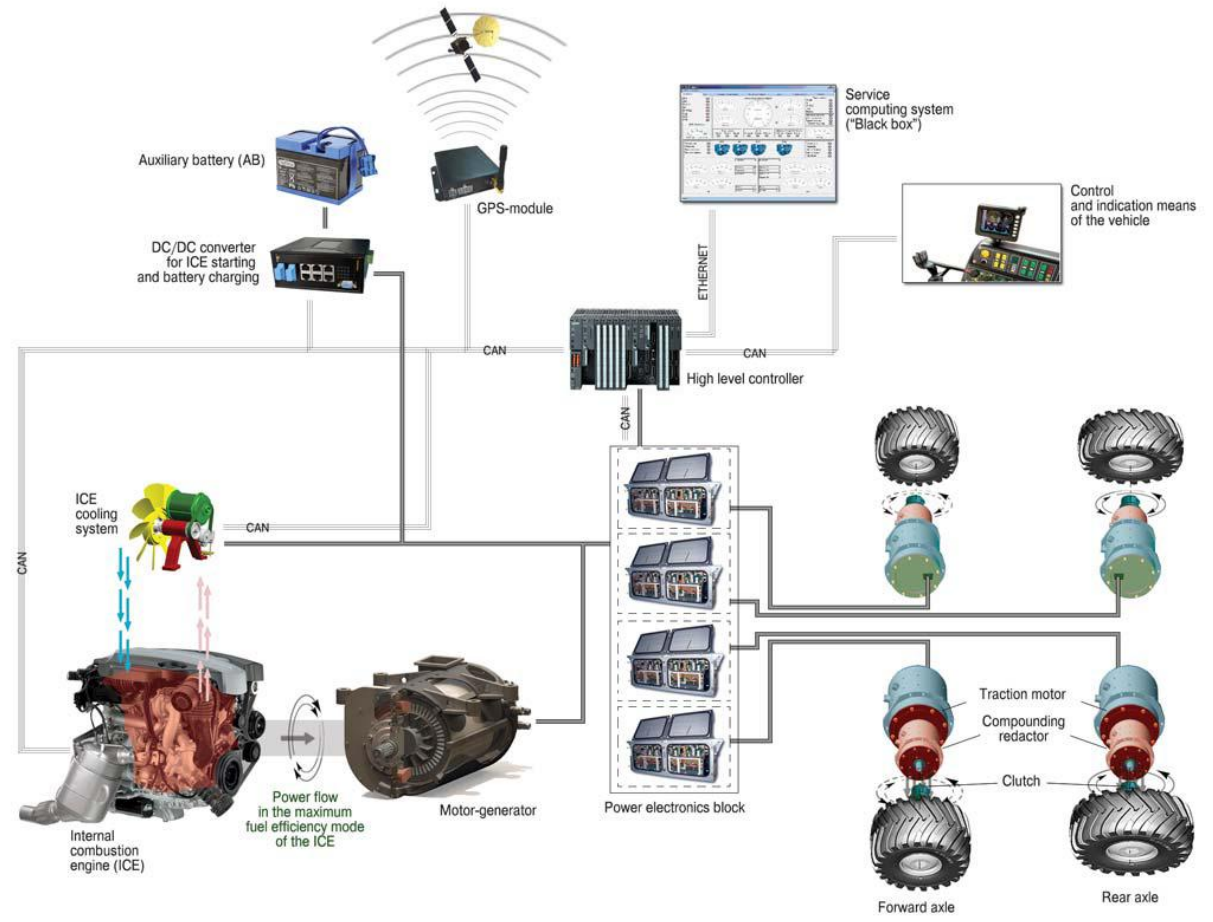

Figure 4 Block-diagram of the TEES of the EMD-equipped wheeled tractor with individual drive of wheels

\section{CONCLUSION}

Experience of development and introduction of TEES for automatic electromechanical drivetrains without power shifting (CVT) for agricultural tractors (as well as for road, building, forest, multiaxis wheeled vehicles of high load capacity and maneuverability) in our opinion allows to state that such drivetrains are promising, and they will come to change mechanical and hydro-mechanical drivetrains in vehicles of power class above 150 h.p. EMD configuration (gear-drive - like in Belarus-3023 or John Deere 644K or individual wheel drive) will be defined mainly according to an economical parameters.

\section{REFERENCES}

[1] S. Florentsev, A. Pukhovoy I. Uss, D. Izosimov, L. Makarov. Agricultural tractor with pure electromechanical drivetrain. Proceedings 6th
International commercial powertrain conference. May 25-26, 2011. Helmut-List-Halle. Graz, Austria. ICPC 2011-3.3. P. 113 - 120.

[2] S. Florentsev et al. Estimation of results and potential of electromechanical drivetrain in agricultural tractors. Proceedings 7th International commercial powertrain conference. May 22-23, 2013. Helmut-List-Halle. Graz, Austria. ICPC 2013 - 2.8. P. 93 - 103.

[3] "Exklusiver Fahrbericht Prototyp Belarus 3023: Stufenlos mit dem Strom", PROFI June: 34-37, 2010.

[4] S. Florentsev, A. Pukhovoy, I. Uss, D. Izosimov, L. Makarov. Agricultural tractor with pure electromechanical drivetrain. SAE 2011 Commercial Vehicle Engineering Congress. September 13-14. 2011. Rosemont. Illinois USA. Session CV707. Paper No. 2011-01-2296. Publication SAE 12CV-0091.

[5] S. Florentsev, D. Izosimov I. Ksenevich. Design Philosophy of Complete Traction Electric Equipment Sets for Hybrid Vehicles. SAE International. Publ. No. 2011-24-0001.

[6] Florentsev Stanislav; Izosimov Dmitry; Ksenevich Ivan. The design concept of complete traction electric equipment sets for hybrid vehicles. FISITA 2012 World Automotive Congress. 27 - 30 November, Beijing. China. 2012. Publ. F2012 - C03 - 002. 